\title{
КЛИНИЧЕСКИЙ ОПЫТ ВЕДЕНИЯ БЕРЕМЕННЫХ С НАДПОЧЕЧНИКОВОЙ НЕДОСТАТОЧНОСТЬЮ РАЗЛИЧНОГО ГЕНЕЗА
}

\author{
Сазонова А.И., Есаян Р.М.
}

ФГБУ «Национальный медицинский исследовательский центр акушерства, гинекологии и перинатологии имени академика В.И. Кулакова» Министерства Здравоохранения РФ, Москва

ЦЕЛЬ: исследование особенностей протекания беременности у женщин с гипокортицизмом

МАТЕРИАЛЫ И МЕТОДЫ: в исследование включено 11 женщин с хронической надпочечниковой недостаточностью (ХНН), наблюдавшихся во время беременности в ФГБУ «НМИЦ акушерства, гинекологии и перинатологии им. ак. В.И. Кулакова» МЗ РФ в 2017-2020 гг. Из них болезнь Аддисона n=2, аутоиммунный полигландулярный синдром 2 типа (АПС) $n=3$, классические формы врожденной дисфункции коры надпочечников (ВДКН) $\mathrm{n}=6$. Количество беременностей за указанный период $-13,3$ в настоящее время пролонгируются (3-й триместр). Изучены дозы глюко- и минералокортикоидной (ГК и МК) терапии, особенности протекания беременностей, метод родоразрешения, исходы.

PЕЗУЛЬТАТЫ: средний возраст беременных составил 29 лет (24-35). Самопроизвольные беременности $\mathrm{n}=8$, ЭКО $\mathrm{n}=4$, стимуляция овуляции $\mathrm{n}=1$. На этапе планирования беременности все пациентки получали ГК терапию (кортеф $n=6$, преднизолон $n=3$, комбинация корте $\phi$ метипред $n=2$ ), МК терапию (кортинеф $\phi=6)$, препараты левотироксина в случае АПC ( $=3)$. Средние дозы ГК в пересчете на гидрокортизон на этапе планирования составили 33,3 мг/сут (15-45), МК 107 мкг/сут (25-150), левотироксин 75 мкг/сут. В 1 триместре беременности отмечалась декомпенсация ХНH у 3 женщин (у 2-х выраженный ранний токсикоз, купирован инфузионной терапией и увеличением дозы ГК до 40-60 мг/сут, у 1-й развитие комы с потребностью в в/в инфузии ГК в условиях реанимации). У остальных в 1 триместре коррекции дозы ГК не требовалось. Во 2 триместре у 3 женщин отмечалось увеличение потребности в МК до 125-200 мкг/сут в связи с гипотензией. Однако у 1-й пациентки с сольтеряющей формой ВДКН развилась хроническая артериальная гипертензия с 13 недель, что потребовало снижения дозы МК до полной отмены на 20 неделе. На 30-32 неделях на фоне интеркуррентных заболеваний у 2 пациенток с ВДКН развилась декомпенсация ХНН с потребностью в инфузии ГК в/в. Родоразрешение $(\mathrm{n}=10)$ проводилось на 37-40 неделях, естественные роды $\mathrm{n}=2$, путем операции кесарева сечения $\mathrm{n}=8$. Родилось 10 доношенных детей (4 девочки, 6 мальчиков), средним весом 3095 г (2123-4018). В родах проводилась профилактика декомпенсации ХНH (Солу-кортеф в/в, 100-200 мг/сут). После родоразрешения у 2 пациенток, несмотря на профилактику, развилась декомпенсация, остальные переведены на пероральный прием препаратов со 2х суток без особенностей.

ВЫВОды: ведение беременности у пациенток с гипокортицизмом требует индивидуализированного подхода. Основную сложность представляет 1 триместр, т.к. симптомы раннего токсикоза могут маскировать декомпенсацию ХНH. Во 2 триместре следует мониторировать необходимость повышения дозы в МК по уровню АД. В 3 триместре, в родах и раннем послеродовом периоде следует учитывать возрастающую потребность в ГК и своевременно проводить коррекцию. Срок родоразрешения определяется акушерскими показаниями, выбор метода зависит от диагноза: обязательное оперативное родоразрешение показано только в случае ВДКН с пластикой наружных половых органов в анамнезе. 